5. Griffin JW, Goren E, Schaumburg H, Engel WK, Loriaux L. Adrenomyeloneuropathy: a probable variant of adrenoleukodystrophy. I. Clinical and endocrinologic aspects. Neurology 1977; 27:1107-13

6. Huckman MS, Wong PW, Sullivan T, Zeller P, Geremia GK. Magnetic resonance imaging compared with computed tomography in adrenoleukodystrophy. Am J Dis Child 1986; 140:1001-3.

7. Whitcomb RW, Linehan WM, Knazek RA. Effects of long-chain, saturated fatty acids on membrane microviscosity and adrenocorticotropin responsiveness of human adrenocortical cells in vitro. J Clin Invest 1988; 81:1858 .
8. Van Duyn MA, Moser AE, Brown FR IIl, Sacktor N, Liu A, Moser HW. The design of a diet restricted in saturated very long-chain fatty acids: therapeutic application in adrenoleukodystrophy. Am J Clin Nutr 1984; 40:277-84.

9. Rizzo WB, Phillips MW, Dammann AL, et al. Adrenoleukodystrophy: dietary oleic acid lowers hexacosanoate levels. Ann Neurol 1987; 21:2329.

10. Moser AE, Borel J, Odone A, et al. A new dietary therapy for adrenoleukodystrophy: biochemical and preliminary clinical results in 36 patients. Ann Neurol 1987; 21:240-9.

\title{
TREATMENT OF VISCERAL LEISHMANIASIS WITH PENTAVALENT ANTIMONY AND INTERFERON GAMMA
}

\author{
Roberto Badaro, M.D., Ernesto Falcoff, M.D., Fernando S. Badaro, M.D., \\ Edgar M. Carvalho, M.D., Diana Pedral-Sampaio, M.D., Aldina Barral, M.D., \\ Jose S. Carvalho, M.D., Manoel Barral-Netto, M.D., Maud Brandely, M.D., \\ Luciana Silva, M.D., Jose C. Bina, M.D., Rodolfo Teixeira, M.D., Rebeca Falcoff, M.D., \\ Heonir Rogha, M.D., John L. Ho, M.D., and Warren D. Johnson, Jr., M.D.
}

\begin{abstract}
Acute visceral leishmaniasis is associated with an antigen-specific immunosuppression of mononuclear cells as evidenced by defective in vitro production of interferon gamma. We evaluated treatment with recombinant human interferon gamma in combination with conventional pentavalent antimony therapy in patients with visceral leishmaniasis.
\end{abstract}

Six of eight patients with visceral leishmaniasis (mean duration, 17 months) that had been unresponsive to multiple courses of pentavalent antimony responded to treatment with recombinant human interferon gamma (100 to $400 \mu \mathrm{g}$ per square meter of body-surface area per day) in addition to pentavalent antimony ( $20 \mathrm{mg}$ per kilogram of body weight per day) for 10 to 40 days. The other two patients improved initially but then relapsed and required

$\mathrm{V}$ ISCERAL leishmaniasis is caused by obligate intracellular protozoa of the genus leishmania. The disease is worldwide in distribution and occurs in parts of Africa, North and South America, eastern and southern Europe, and Asia. ${ }^{1-3}$ Visceral leishmaniasis is characterized by fever, hepatosplenomegaly, anemia, and leukopenia. Pentavalent antimonial drugs have been the preferred therapy for more than 40 years. Antimonials are potentially toxic, however, and therapeutic failures occur in up to 15 percent of patients. ${ }^{1,4}$ Amphotericin B and pentamidine are alternative therapies but are also associated with toxicity.

In the present study, we used recombinant interferon gamma in combination with pentavalent antimony to treat patients with visceral leishmaniasis. The rationale for this regimen is based on the observation that during acute visceral leishmaniasis, peripheral-blood mononuclear cells fail to recognize leishmania antigen (as measured by $\mathrm{T}$-cell blastogenesis

From the Universidade Federal da Bahia, Salvador, Brazil (R.B., F.S.B. E.M.C., D.P.-S., A.B., J.S.C., M.B.-N., L.S., J.C.B., R.T., H.R.); the Institut Curie, Paris (E.F., R.F.); Cornell University Medical College, New York (R.B., J.L.H., W.D.J.); and Roussel-UCLAF, Romainville, France (M.B.). Address reprint requests to Dr. Roberto Badaro at Cornell University Medical College, Division of International Medicine, 1300 York Ave., New York, NY 10021.

Supported by a grant (AI-16282) from the National Institutes of Health. treatment with amphotericin B. Eight of nine additional patients with previously untreated severe visceral leishmaniasis were also successfully treated with the combination of interferon gamma and pentavalent antimony. The 14 patients who responded to this regimen had marked improvement in symptoms and in measures of anemia and leukopenia, as well as weight gain, a decrease in spleen size, and an absence or reduction of leishmanias in splenic aspirates. These patients had no recurrence of illness after a mean ( $\pm S E$ ) follow-up of $8 \pm 1$ months. Fever was the only major side effect of interferon gamma.

We conclude that the combination of interferon gamma and pentavalent antimony is effective in treating seriously ill patients with refractory or previously untreated visceral leishmaniasis. (N Engl J Med 1990; 322:16-21.)

and the production of interleukin-2 and interferon gamma) ${ }^{5-7} \mathrm{~T}$-cell recognition of mitogen and unrelated antigens is unaffected ${ }^{7}$; the antigen-specific immunosuppression is cell-mediated. ${ }^{8}$ Defects in the functioning of macrophages have been observed in vitro; they include decreased production of interleukin-1, decreased expression of major histocompatibility complex Class II molecules, and increased generation of prostaglandin $\mathrm{E}_{2}{ }^{9-13}$ Exogenously administered interferon gamma augments the capacity of macrophages to eliminate leishmania infection in in vitro models and acts synergistically with pentavalent antimony. ${ }^{14-17}$ Finally, the safety of parenteral recombinant human interferon gamma has been demonstrated in patients with leprosy, cancer, the acquired immunodeficiency syndrome, and chronic granulomatous disease. $^{18-21}$

\section{Methods}

The study population was made up of eight patients with visceral leishmaniasis that had been refractory to multiple courses of conventional therapy with pentavalent antimony (Group 1) and nine severely ill patients with previously untreated visceral leishmaniasis (Group 2). The patients' median age was 6 years (range, 2 to 23). The mean $( \pm \mathrm{SD})$ duration of illness was $17 \pm 9$ months (range, 6 to 30 ) in Group 1 and $6 \pm 6$ months (range, 1 to 12 ) in Group 2. Thirteen patients were male and four female. All the patients were 
hospitalized at the Hospital Professor Edgard Santos in Salvador, Bahia, Brazil, during 1986 through 1988. Sixteen patients were from the state of Bahia and one patient was from the state of Sergipe. Informed consent was obtained from all patients or their guardians, and the study was approved by the committees on human rights of Cornell University Medical College and the University of Bahia.

\section{Diagnostic Criteria}

All the patients had clinical manifestations of visceral leishmaniasis, including fever, hepatosplenomegaly, anemia, and leukopenia. Serologic tests for leishmania antibodies by enzyme-linked immunosorbent assay were positive, and leishmania amastigotes were demonstrated in Giemsa-stained direct smears of splenic aspirates from all patients. ${ }^{22}$ To obtain the size of the spleen, we measured the span below the left costal margin at the anterior axillary line. The splenic-aspiration procedure followed the protocol of Chulay and Bryceson. ${ }^{23}$ A platelet count $\geqslant 80,000$ per cubic millimeter and prothrombin activity $\geqslant 60$ percent of control were prerequisites for splenic aspiration. Leishmania amastigotes were measured in a splenic-aspirate smear over a period of 30 minutes by scanning 1000 oil-immersion fields $(\times 10$ eyepiece, $\times 100$ oil objective $)$. The grading system (leishmania index) scored the smears logarithmically as follows: zero (indicating no parasites per 1000 fields), $1+$ ( 1 to 10 parasites per 1000 fields), $2+(1$ to 10 parasites per 100 fields), $3+$ ( 1 to 10 parasites per 10 fields $), 4+$ ( 1 to 10 parasites per field), $5+(10$ to 100 parasites per field $)$, and $6+(>100$ parasites per field). Leishmanias were cultured, in Novy, McNeal, and Nicolle medium, from the splenic aspirates of 14 of the 17 patients. 'The cultures of aspirates from the remaining three patients were contaminated.

A patient was considered to have visceral leishmaniasis refractory to antimony therapy if he or she had persistent clinical manifestations of visceral leishmaniasis and amastigotes in a splenic aspirate after receiving two or more documented courses of pentavalent antimony ( 20 to $30 \mathrm{mg}$ per kilogram of body weight per day) totaling at least 20 days; such patients were assigned to Group 1. Patients with untreated leishmaniasis (Group 2) were severely ill, had hemorrhagic manifestations (epistaxis or petechiae), and had a leishmania index of at least $3+$ on examination of their splenic aspirates.

\section{Drugs and Therapy}

Recombinant human interferon gamma (RU 42369, RousselUCLAF, Romainville, France) is produced from a strain of Escherichia coli transfected with a plasmid into which the gene coding for the synthesis of human interferon gamma has been inserted. The protein is nonglycosylated and contains 143 amino acids. The molecular weight is 17,000 by sodium dodecyl sulfate-polyacrylamide gel electrophoresis and 34,000 by gel filtration in the native form. The specific activity is $2 \times 10^{7} \mathrm{U}$ per milligram. The pentavalent antimony used was $\mathrm{N}$-methylglucamine antimoniate sodium (Glucantime, Rhodia, São Paulo, Brazil) containing $85 \mathrm{mg}$ of pentavalent antimony per milliliter.

The patients with refractory visceral leishmaniasis (Group l) received daily intramuscular injections of interferon gamma (100 $\mu \mathrm{g}$ per square meter of body-surface area) and intravenous infusions of pentavalent antimony ( $20 \mathrm{mg}$ per kilogram per day) for 10 days. An exception was the first patient treated, who received interferon at a dose of $50 \mu \mathrm{g}$ per square meter per day. On the 10th day the patients were reevaluated and a second splenic aspirate was obtained. If the patient was clinically improved but the splenic aspirate remained positive for leishmanias, the combination therapy was continued at the same dosage for 10 more days (a total of 20 days). After 20 days, if the patient was clinically improved but the splenic aspirate was still positive, the interferon-antimony therapy was continued for 10 to 20 more days, with an increase in the dose of gamma interferon to $400 \mu \mathrm{g}$ per square meter per day (Patients 4 and 5). If the signs and symptoms of leishmaniasis persisted and the leishmania index in the splenic aspirate was $3+$ or higher after 20 days or more, the interferon-antimony treatment was considered to have failed (Patients 6 and 7).

Patients in Group 2 received interferon $(100 \mu \mathrm{g}$ per square meter per day) and pentavalent antimony ( $20 \mathrm{mg}$ per kilogram per day) for 10 days. If the patient was afebrile (temperature $\leqslant 37.5^{\circ} \mathrm{C}$ for 24 hours) and had no evidence of bleeding and the splenic aspirate was negative, both drugs were discontinued after 10 days (Patients 10 and 16). However, if the leishmania index in the splenic aspirate was $1+$ or $2+$, interferon was stopped and pentavalent antimony was continued (at a dose of $20 \mathrm{mg}$ per kilogram per day) for 10 more days (Patients 11, 12, 13, 15, and 17). In two patients (Patients 9 and 14), who had clinical improvement but an index of $3+$ in the splenic aspirate, interferon and antimony were both continued for an additional 10 days. Interferon was inadvertently discontinued on day 6 in Patient 12.

\section{Clinical-Response Criteria}

Clinical cure or successful therapy was defined by the maintenance of a temperature $<37.5^{\circ} \mathrm{C}$ for 24 hours or more, a decrease in the size of the spleen, the absence of bleeding, a leishmania index of zero to $1+$ in the splenic aspirate, and at least one of the following: a white-cell count $4.0 \times 10^{6}$ per liter, hematocrit $\geqslant 30$ percent, or a 10 percent weight gain. The absence of signs and symptoms of leishmaniasis for at least three months was also required after the criteria just described were met.

\section{Laboratory Analysis}

The laboratory tests performed routinely in our study were a white-cell count, differential white-cell count, hematocrit, hemoglobin measurement, biochemistry profile, and urinalysis; a chest $x$-ray film was also obtained. Electrocardiography was performed in all patients. Lymphocyte-blastogenesis assays were performed on mononuclear cells obtained from heparinized venous blood after Ficoll-Hypaque density-gradient centrifugation as previously described. ${ }^{7}$ The cells were stimulated with Leishmania donovani chagasi soluble antigen ${ }^{7}$ in a concentration of $1 \mu \mathrm{g}$ per milliliter of culture medium for five days. Uptake of $\left[{ }^{3} \mathbf{H}\right]$ thymidine (New England Nuclear, Boston) was measured, and the results were expressed as a stimulation index (counts per minute of stimulated culture/counts per minute of unstimulated culture). A stimulation index $\geqslant 4$ was considered positive for leishmanias.

\section{Historical Controls}

A total of 101 patients with a diagnosis of visceral leishmaniasis were hospitalized at the Hospital Professor Edgard Santos during the decade before the study (1976 through 1985). Fourteen patients were excluded because they either received fewer than 10 days of antimony therapy or did not have diagnostic results on bone marrow aspiration. Splenic aspirations were not performed in Bahia until 1986. The charts of 87 patients were reviewed for age, duration of illness, history of antimony therapy, and therapeutic response. Of these 87 patients, 55 were selected by a random-table method for a more detailed analysis of clinical characteristics before and after antimony therapy.

\section{Statistical Analysis}

The difference in response rates was compared by the two-tailed chi-square test. Differences in other variables were compared by Student's t-test.

\section{Results}

The first patient to receive interferon gamma and antimony had refractory visceral leishmaniasis and had received seven courses of antimony (totaling 90 days) during the previous 20 months (Table 1). Despite therapy, she had persistent fever, abdominal swelling, weight loss, pancytopenia, and epistaxis. Examination of a splenic aspirate showed a leishmania index of $5+$. She underwent 10 days of treatment with interferon gamma (50 $\mu \mathrm{g}$ per square meter per day, given intramuscularly) and pentavalent antimony (20 mg per kilogram per day, given intravenously). One day after the completion of therapy, a splenic aspirate was negative for leishmanias. On the basis of this dra- 
Table 1. Patient Characteristics and Results of Treatment with Interferon Gamma and Antimony in Patients with Refractory Visceral Leishmaniasis (Group 1) or Previously Untreated Visceral Leishmaniasis (Group 2).*

\begin{tabular}{|c|c|c|c|c|c|c|c|}
\hline \multirow[t]{3}{*}{ Patient No. } & \multirow[t]{3}{*}{ AGE (YR) } & \multirow[t]{3}{*}{$\begin{array}{l}\text { DURATION OF } \\
\text { ILLNESS (MO) }\end{array}$} & \multicolumn{3}{|c|}{ Previous Antimony Trearment } & \multicolumn{2}{|c|}{ Study Treatment } \\
\hline & & & NO. OF COURSES & $\begin{array}{c}\text { DOSE } \\
(\mathrm{mg} / \mathrm{kg} / \text { day })\end{array}$ & $\begin{array}{l}\text { TOTAL NO. } \\
\text { OF DAYS }\end{array}$ & INTERFERON GAMMA & $\begin{array}{c}\text { ANTIMONY } \\
(20 \mathrm{mg} / \mathrm{kg} / \text { day })\end{array}$ \\
\hline & & & & & & dose ( $\mu g / d a y)$ & no. of duys \\
\hline
\end{tabular}

Refractory disease (Group 1)

1
2
3
4
5
6
7
8
Mean

$\begin{array}{rr}8 & 24 \\ 3 & 15 \\ 2 & 10 \\ 11 & 18 \\ 6 & 24 \\ 12 & 30 \\ 5 & \\ 5 & \\ 6.5 & \end{array}$

$\begin{array}{rl}24 & 7 \\ 15 & 6 \\ 10 & 3 \\ 18 & 3 \\ 24 & 6 \\ 30 & \\ 9 & 3 \\ 6 & 3 \\ 17 & 2 \\ & 4.1\end{array}$

$\begin{array}{ll}20 & 90 \\ 16 & 40 \\ 30 & 20 \\ 16 & 40 \\ 24 & 60 \\ 18 & 40 \\ 16 & 40 \\ 20 & 40 \\ 20 & 46\end{array}$

Previously untreated disease

\section{(Group 2)}

9
10
11
12
13
14
15
16
17

$\begin{array}{rc}7 & 3 \\ 2 & 1 \\ 13 & 6 \\ 23 & 12 \\ 3 & 6 \\ 6 & 12 \\ 12 & 7 \\ 17 & 2 \\ 6 & \text { Unknown } \\ 9.8 & 6\end{array}$

$\begin{array}{lll}= & = & = \\ = & = & = \\ = & = & = \\ = & = & = \\ = & = & =\end{array}$

LABORATORY AND Clinical INDEXES

$\begin{array}{rll}35 & 10 & 10 \\ 50 & 20 & 20 \\ 50 & 20 & 20 \\ 125 & 20 & 40 \\ 500 & 20 & \\ 50 & 20 & 30 \\ 200 & 10 & \\ 125 & 40 & 60 \\ 500 & 20 & \\ 100 & 20 & 20 \\ 60 & 20 & 20 \\ 109 & 28 & 28\end{array}$

WHITE-CELL COUNT $\left(\times 10^{6} /\right.$ iter) HEMATOCRIT $(\%)$ SIZE OF SPLEEN $(\mathrm{cm})$ WEIGHT $(\mathrm{kg})$ LEISHMANIA INDEX LYMPHOCYTE SI

value before treatment/value after treatment

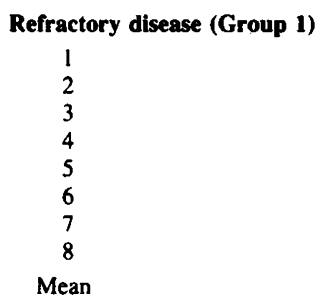

$\begin{array}{cl}2 / 6 & 29 / 35 \\ 3 / 6 & 12 / 37 \dagger \\ 4 / 6 & 22 / 26 \\ 5 / 6 & 31 / 38 \\ 3 / 5 & 21 / 20 \\ 2 / 5 & 29 / 25 \\ 2 / 5 & 17 / 39 \dagger \\ 4 / 6 & 20 / 34 \\ 3.1 / 5.6 & 23 / 32\end{array}$

$12 / 4$
$13 / 7$
$14 / 10$
$11 / 6$
$13 / 8$
$20 / 16$
$18 / 14$
$9 / 6$
$14 / 9$

$17 / 19$
$12 / 14$
$10 / 12$
$22 / 24$
$15 / 16$
$34 / 36$
$16 / 16$
$17 / 17$
$18 / 19$

$5+/ 0$
$6+/ 0$
$5+/ 0$
$6+/ 1+$
$6+/ 1+$
$6+/ 4+$
$6+/ 3+$
$4+/ 0$
$5.5+/ 1.1+$

$1 / 13$
$1 / 18$
$2 / 4$
$1 / 1$
$2 / 9$
$3 / 2$
$2 / 7$
No data
$1.7 / 7.7$

$$
\begin{gathered}
17 \\
13 \\
10 \\
7 \\
4 \\
11 \\
16 \\
3 \\
10.1
\end{gathered}
$$

Previously untreated disease

(Group 2)

9
10
11
12
13
14
15
16
17

$\begin{array}{cl}3 / 8 & 28 / 34 \\ 4 / 6 & 28 / 36 \\ 2 / 1 & 29 / 32 \\ 3 / 2 & 27 / 29 \\ 3 / 5 & 25 / 33 \\ 4 / 3 & 31 / 31 \dagger \\ 2 / 4 & 27 / 31 \\ 2 / 6 & 20 / 28 \\ 1 / 15 & 14 / 27 \dagger \\ 2.6 / 6.0 & 25 / 31\end{array}$

$12 / 4$
$6 / 1$
$10 / 7$
$11 / 4$
$16 / 10$
$8 / 3$
$12 / 10$
$18 / 1$
$22 / 15$
$13 / 6$

$23 / 25$
$12 / 13$
$28 / 31$
$56 / 61$
$13 / 14$
$15 / 16$
$27 / 29$
$40 / 49$
$11 / 15$
$25 / 28$

$4+10$
$3+/ 0$
$5+10$
$4+/ 0$
$4+10$
$5+/ 0$
$5+13+$
$5+10$
$4+/ 0$
$4.3+10.1+$

$<1 / 8$
$1 / 4$
$2 / 36$
$4 / 78$
$8 / 74$
$1 / 9$
$1 / 3$
$2 / 20$
No data
$2.4 / 29.0$

8
7
7
10
5
4
5
5
6
6.3

*SI denotes stimulation index. Pretreatment studies were performed within one week of the initiation of combination therapy, and post-treatment studies were done within one week of the completion of therapy, except for the stimulation index, which was determined 20 to 30 days after treatment was completed.

tThe patient received a transfusion during therapy.

matic response, we subsequently treated seven more patients with refractory visceral leishmaniasis (Group 1) and nine patients with previously untreated visceral leishmaniasis (Group 2). The patients' clinical characteristics and laboratory-test results are summarized in Table 1.

Patients in Group 1 had a mean age $( \pm S D)$ of $6.5 \pm 3.6$ years. The duration of their illness was $17 \pm 9$ months, and they had previously undergone $46 \pm 21$ days of antimony therapy. They had a mean hematocrit of $23 \pm 7$ percent, a spleen size of $14 \pm 4 \mathrm{~cm}$, and a leishmania index of $5.5+(\mathrm{SD}, 0.8+)$ in splenic aspirates. Despite their refractory disease, the combination of interferon and antimony resulted in a dramatic improvement in the clinical signs and symptoms of all patients in Group 1. Six of the eight patients in Group 
1 have remained asymptomatic for a mean of $10 \pm 5$ months (range, 3 to 17). The remaining two patients in Group 1 (Patients 6 and 7) had initial clinical improvement with combined therapy. Patient 6 became afebrile after 40 days of treatment with interferon and antimony and had an increased leukocyte count, but leishmanias persisted in the splenic aspirate (leishmania index, $1+$ ). The patient had a clinical relapse within several weeks, with a leishmania index of $4+$ in the splenic aspirate. An additional 20 days of combined therapy did not alter the leishmania index. The patient then received amphotericin B (total dose, 700 $\mathrm{mg}$ ), with a resulting decrease in the leishmania index to $1+$ after 35 days of therapy. Three months after the end of amphotericin B therapy, leishmanias could no longer be found in the splenic aspirate. Patient 7 also improved clinically after combined therapy, and the leishmania index in the splenic aspirate decreased from $6+$ to $3+$. During the next two weeks, however, his symptoms increased, and the leishmania index in a second splenic aspirate was $5+$. Amphotericin B was given for 45 days (total dose, $450 \mathrm{mg}$ ), with a resulting reduction of the index to $1+$. At the three-month follow-up, the patient's spleen had diminished markedly in size, and leishmanias were not found in the splenic aspirate.

Patients in Group 2 were severely ill with previously untreated leishmaniasis (Table 1). Their mean duration of illness was $6 \pm 4$ months. They were leukopenic (mean white-cell count, $2.6 \pm 1 \times 10^{6}$ per liter) and anemic (mean hematocrit, $25 \pm 5$ percent) and had splenomegaly (mean span, $13 \pm 5 \mathrm{~cm}$ ), with a large parasite burden (mean leishmania index, $4.3+[\mathrm{SD}, 0.7+]$ ). Eight of the nine patients in Group 2 were successfully treated with the combination of interferon and antimony, with a mean follow-up of $6 \pm 2$ months (range, 4 to 10). The remaining patient, Patient 15, received the combination therapy for 10 days, with clinical improvement and a reduction in the leishmania index in the splenic aspirate from $5+$ to $1+$. Fever recurred after six weeks, however, and the leishmania index rose again to $3+$. Subsequently, the patient received pentavalent antimony $(20 \mathrm{mg}$ per kilogram per day) for an additional 20 days; the symptoms resolved, and parasites were absent in the splenic aspirate.

Patients in both Group 1 and Group 2 had improvement in most of their laboratory-test results and clinical characteristics immediately after combined therapy. The mean increase from pretreatment values in the white-cell counts was $75 \pm 59$ percent in Group 1 and $170 \pm 223$ percent in Group 2. The mean increase in the hematocrit was 5 percentage points (from 26 to 31 percent) for all except the four patients who received transfusions. All the patients who received combined treatment had a diminution of splenic size within one week of completing therapy. The mean reduction in the longitudinal diameter of the spleen was $40 \pm 16$ percent in Group 1 and $54 \pm 26$ percent in Group 2. Weight gain was noted in 15 of the $17 \mathrm{pa-}$ tients. Finally, in 12 of 15 patients studied, a positive blastogenic response to leishmania antigen (stimulation index $\geqslant 4$ ) was observed 20 to 30 days after the end of therapy.

As another measure of the efficacy of treatment with both interferon and antimony, we compared the clinical response of the patients in Groups 1 and 2 with that of 87 patients with parasitologically confirmed visceral leishmaniasis who were hospitalized at the same hospital during the period from 1976 through 1985. These historical-control patients received pentavalent antimony ( $20 \mathrm{mg}$ per kilogram per day) for a minimum of 10 days. Thirteen of 17 of the patients in Groups 1 and 2 (76 percent) were successfully treated with 20 or fewer days of combined therapy, whereas only 37 of 87 historical-control patients (43 percent) responded to antimony alone within 20 days $(\mathbf{P}=0.001)$. To examine specific manifestations of disease, we compared a randomly selected sample of the control patients who received only antimony with the patients who underwent combined therapy (Table 2 ). The most striking difference was the greater reduction in the size of the spleen observed in the patients who underwent combined therapy as compared with the historical controls $(P=0.0009)$.

The principal side effect of interferon gamma was fever. All patients had elevations of temperature of at least $1^{\circ} \mathrm{C}$ within three to four hours of the interferon injections. The maximal temperature recorded was $40^{\circ} \mathrm{C}$. Although 60 percent of the patients had fever associated with the administration of interferon throughout therapy, fever was readily controlled with either acetaminophen or dipyrone. We noted no seizures, abnormalities of liver chemistry, or renal, cardiac, or pulmonary dysfunction. One patient had mild nausea during interferon therapy. No local reactions were observed at the site of the injection of interferon. Four patients reported a sensation of "ant bites" at the site of the injection, and eight had mild fatigue, myalgia, and headache.

\section{Discussion}

We treated 17 patients with visceral leishmaniasis with a combination of interferon gamma and pentavalent antimony. Six of eight patients (75 percent) with leishmaniasis that had been unresponsive to multiple courses of antimony were successfully treated with this regimen; two patients received additional therapy with amphotericin B. Eight of nine patients (89 percent) with previously untreated severe visceral leishmaniasis were also successfully treated with the combination of interferon gamma and antimony. All 17 patients, including the three patients who later received additional therapy, had improvement in symptoms, signs, and relevant laboratory measures; among other things, they gained weight and had a decrease in both the size of the spleen and the leishmania index in splenic aspirates.

The clinical response of patients with leishmaniasis to interferon and antimony was compared with that of historical-control patients given antimony alone. The combination therapy resulted in a greater reduc- 
Table 2. Response of Patients with Visceral Leishmaniasis to Treatment with Interferon Gamma and Antimony and Response of Historical-Control Patients to Antimony Alone.*

\begin{tabular}{|c|c|c|c|c|c|c|c|}
\hline \multirow[t]{2}{*}{ Patient Group } & \multirow[t]{2}{*}{ No. } & \multirow[t]{2}{*}{ AGE (YR) } & $\begin{array}{l}\text { DURATION OF } \\
\text { ILLNESS (Mo) }\end{array}$ & \multicolumn{3}{|c|}{ LABORATORY INDEXES } & \multirow[t]{2}{*}{$\begin{array}{l}\text { REDLCTION IN SIYE } \\
\text { OF SPLFEN }(\%) \dagger\end{array}$} \\
\hline & & & & HEMATOCRIT (\%) & WHITE-CELL COUNT ( $\times 10^{6} /$ LITER $)$ & SIZE OF SPLEEN (CM) & \\
\hline & & & \multicolumn{5}{|c|}{ value before treatmentivalue after treatment } \\
\hline Group 1 & 8 & $6.5 \pm 3.5 \dagger$ & $17.0 \pm 8.5$ & $22.0 \pm 7.0 / 32.0 \pm 7.0$ & $3.1 \pm 1.2 / 5.6 \pm 0.6$ & $13.7 \pm 3.6 / 8.8 \pm 4.4$ & $40 \pm 16$ \\
\hline Group 2 & 9 & $9.8 \pm 7.0$ & $6.1 \pm 4.1$ & $25.0 \pm 5.0 / 31.0 \pm 3.0$ & $2.6 \pm 0.9 / 6.0 \pm 4.0$ & $12.7 \pm 5.0 / 6.0 \pm 4.8$ & $54 \pm 26$ \\
\hline Historical controls & 55 & $10.2 \pm 6.8$ & $7.1 \pm 5.6$ & $23.9 \pm 4.9 / 29.6 \pm 5.4$ & $3.1 \pm 1.7 / 4.8 \pm 1.9$ & $12.5 \pm 4.2 / 9.8 \pm 5.1$ & $24 \pm 25$ \\
\hline
\end{tabular}

*Plus-minus values are means $\pm \mathrm{SD}$. See the text for an explanation of the patient groups. The size of the spleen was measured as the span below the left costal margin at the anterior axillary line.

$\dagger \mathrm{P}=0.0009$ for the comparison of Groups 1 and 2 with the historical controls; $P=0.004$ for the comparison of Group 1 with the historical controls; $P=0.001$ for the comparison of Group 2 with the historical controls.

tion in the size of the spleen and may have reduced the duration of treatment, since 76 percent of the patients in Groups 1 and 2 were successfully treated with 20 or fewer days of therapy, as compared with 43 percent of the historical control patients. This observation requires confirmation in a double-blind comparison of interferon gamma and antimony with antimony alone.

Fever was the most common adverse reaction to interferon but was readily controlled with antipyretic agents. Treatment with interferon (up to $400 \mu \mathrm{g}$ per square meter per day) had no other clinically important toxic effects over a 10-to-60-day interval. Constitutional symptoms of fatigue, myalgia, and headache were common but not severe. Thus, the combination of interferon and antimony was efficacious and had no important toxic effects.

Interferon gamma is a glycoprotein with a molecular weight of 20,000 to 25,000 whose chief physiologic source is $\mathrm{T}$ cells. It has been shown to inhibit cell growth in the presence of lymphotoxin, ${ }^{24}$ induce the expression of major histocompatibility complex Class I and Class II molecules, ${ }^{25,26}$ prime macrophages for killing tumor cells ${ }^{27}$ and enhance natural-killer-cell cytotoxicity. ${ }^{28}$ In addition to its antiviral activity, it enhances the antimicrobial action of macrophages and a wide variety of host cells against approximately 20 different microbial pathogens, including both bacteria and protozoa. ${ }^{29}$ Studies in patients with cancer have demonstrated that interferon gamma has antitumor effects. ${ }^{30,31}$ The administration of interferon gamma partially corrects the phagocytic-oxidativemetabolic defect in patients with X-linked chronic granulomatous disease. ${ }^{21}$ In patients with lepromatous leprosy, interferon gamma induces histologic changes in the skin at the injection site that are "similar to certain features of delayed-type hypersensitivity reactions of tuberculoid leprosy." 19

A potential explanation for the efficacy of interferon gamma in our study is that it enhances the intracellular killing of leishmanias. The normal immune response requires the interaction of macrophages and T cells. ${ }^{32,33}$ This response is mediated by presentation by the macrophage of processed antigen in conjunction with major histocompatibility complex Class II molecules to the $\mathrm{T}$-cell receptor, in concert with the elaboration of interleukin-1 by activated macrophages. T-cell activation is triggered, resulting in a blastogenic response and the production of interleukin-2, interferon gamma, and other cytokines. Interferon gamma enhances the ability of macrophages to eliminate intracellular pathogens. ${ }^{29}$ Although it is likely that the administration of interferon corrects the immunosuppression associated with acute visceral leishmaniasis, we cannot exclude other explanations, such as the intracellular accumulation of antimony, an alteration in the pharmacokinetics of antimony, or a synergistic effect of interferon and antimony.

We are indebted to Olivia Bacellar and Gloria Orge for technical assistance; to Jackson Lemos Moreira, Edda Morgan, and Betty Gittens for assistance in the preparation of the manuscript; and to the INSERM Institut-Paris, in collaboration with RousselUCLAF, which provided the recombinant human interferon gamma.

\section{REFERENCES}

1. Marsden PD, Jones TC. Clinical manifestations, diagnosis and treatment of leishmaniasis. In: Chang K-P, Bray RS, eds. Leishmaniasis. Vol. 1 of Ruitenberg EJ, MacInnis AJ, eds. Human parasitic diseases. Amsterdam: Elsevier, 1985:183-98.

2. Marsden PD. Selective primary health care: strategies for control of disease in the developing world. XIV. Leishmaniasis. Rev Infect Dis 1984; 6:73644.

3. Eickhoff TC, Young LS. Gaps in therapy for infectious disease: conference summary. J Infect Dis 1982; 145:407-12.

4. Bryceson AD, Chulay JD, Mugambi M, et al. Visceral leishmaniasis unresponsive to antimonial drugs. II. Response to high dosage sodium stibogluconate or prolonged treatment with pentamidine. Trans Soc Trop Med Hyg 1985; 79:705-14.

5. Carvalho EM, Teixeira RS, Johnson WD Jr. Cell-mediated immunity in American visceral leishmaniasis: reversible immunosuppression during acute infection. Infect Immun 1981; 33:498-500.

6. Ho M, Koech DK, Iha DW, Bryceson ADM. Immunosuppression in Kenyan visceral leishmaniasis. Clin Exp Immunol 1983; 51:207-14.

7. Carvalho EM, Badaro R, Reed SG, Jones TC, Johnson WD Jr. Absence of gamma interferon and interleukin 2 production during active visceral leishmaniasis. J Clin Invest 1985; 76:2066-9.

8. Carvalho EM, Bacellar O, Barral A, Badaro R, Johnson WD Jr. Antigenspecific immunosuppression in visceral leishmaniasis is cell mediated. J Clin Invest 1989; 83:860-4.

9. Crawford GD, Wyler DJ, Dinarello CA. Parasite-monocyte interactions in human leishmaniasis: production of interleukin- 1 in vitro. J Infect Dis 1985; 152:315-22.

10. Reiner NE. Parasite accessory cell interactions in murine leishmaniasis. I Evasion and stimulus-dependent suppression of the macrophage interleukin I response by Leishmania donovani. J Immunol 1987; 138:1919-25.

11. Reiner NE, Ng W, McMaster WR. Parasite-accessory cell interactions in murine leishmaniasis. II. Leishmania donovani suppresses macrophage expression of class I and class II major histocompatibility complex gene products. J Immunol 1987; 138:1926-32.

12. Reiner NE, Malemud CJ. Arachidonic acid metabolism by murine peritoneal macrophages infected with Leishmania donovani: in vitro evidence for parasite-induced alterations in cyclooxygenase and lipoxygenase pathways. J Immunol 1985; 134:556-63.

13. Reiner NE, Ng W, Ma T, McMaster WR. Kinetics of $\gamma$-interferon binding and induction of major histocompatibility complex class II mRNA in leishmania-infected macrophages. Proc Natl Acad Sci U S A 1988; 85:43304. 
14. Murray HW, Rubin BY, Rothermel CD. Killing of intracellular Leishmania donovani by lymphokine-stimulated human mononuclear phagocytes: evidence that interferon-gamma is the activating lymphokine. J Clin Invest 1983; 72:1506-10.

15. Murray HW, Spitalny GL, Nathan CF. Activation of mouse peritoneal macrophages in vitro and in vivo by interferon-gamma. J Immunol 1985; 134:1619-22

16. Hoover DL, Nacy CA, Meltzer MS. Human monocyte activation for cytotoxicity against intercellular Leishmania donovani amastigotes: induction of microbicidal activity by interferon-gamma. Cell Immunol 1985; 94:50011.

17. Murray HW, Berman JD, Wright SD. Immunochemotherapy for intracellular Leishmania donovani infection: gamma interferon plus pentavalent antimony. J Infect Dis 1988; 157:973-8.

18. Nathan CF, Horowitz CA, de la Harpe J, et al. Administration of recombinant interferon gamma to cancer patients enhances monocyte secretion of hydrogen peroxide. Proc Natl Acad Sci U S A 1985; 82:8686-90.

19. Nathan CF, Kaplan G, Levis WR, et al. Local and systemic effects of intradermal recombinant interferon- $\gamma$ in patients with lepromatous leprosy. N Engl J Med 1986; 315:6-15.

20. Murphy PM, Lane HC, Gallin JI, Fauci AS. Marked disparity in incidence of bacterial infections in patients with the acquired immunodeficiency syndrome receiving interleukin-2 or interferon- $\gamma$. Ann Intem Med 1988; 108: $36-41$.

21. Ezekowitz RAB, Dinauer MC, Jaffe HS, Orkin SH, Newburger PE. Partial correction of the phagocyte defect in patients with $\mathrm{X}$-linked chronic granulomatous disease by subcutaneous interferon gamma. N Engl J Med 1988; 319:146-51

22. Badaro R, Jones TC, Carvalho EM, et al. New perspectives on a subclinical form of visceral leishmaniasis. J Infect Dis 1986; 154:1003-11.
23. Chulay JD, Bryceson AD. Quantitation of amastigotes of Leishmania donovani in smears of splenic aspirates from patients with visceral leishmaniasis. Am J Trop Med Hyg 1983; 32:475-9.

24. Lee SH, Aggarwal BB, Rinderkneckt E, Assisi F, Chiu H. The synergistic anti-proliferative effect of $\gamma$-interferon and human lymphotoxin. J Immunol 1984; 133:1083-6.

25. Steeg PS, Moore RN, Johnson HM, Oppenheim JJ. Regulation of murine macrophage Ia antigen expression by a lymphokine with immune interferon activity. J Exp Med 1982; 156:1780-93.

26. Gerrard TL, Dyer DR, Zoon KC, zur Nedden D, Siegel JP. Modulation of class I and class II histocompatibility antigens on human T cell lines by IFN \%. J Immunol 1988; 140:3450-5.

27. Spitalny GL, Havell EA. Monoclonal antibody to murine gamma interferon inhibits lymphokine-induced antiviral and macrophage tumoricidal activities. J Exp Med 1984; 159:1560-5.

28. Trinchieri G, Matsumoto-Kobayashi M, Clark SC, Seehra J, London L, Perussia B. Response of resting human peripheral blood natural killer cells to interleukin 2. J Exp Med 1984; 160:1147-69.

29. Nathan C, Yoshida R. Cytokines: interferon- $\gamma$. In: Gallin JI, Goldstein IM, Snyderman R, eds. Inflammation: basic principles and clinical correlates. New York: Raven Press, 1988:229-51.

30. Talpaz M, Kantarjian HM, Kurzrock R, Gutterman J. Therapy of chronic myelogenous leukemia: chemotherapy and interferons. Semin Hematol 1988; 25:62-73.

31. Kaplan EH, Rosen ST, Norris D, Roenigk H Jr, Saks S, Bunn PA Jr. Phase II trial of recombinant human interferon-gamma in cutaneous T-cell lymphoma. Proc Am Soc Clin Oncol 1988; 7:226. abstract.

32. Mizel SB. Interleukin 1 and T cell activation. Immunol Rev 1982; 63:51-72.

33. Durum SK, Schmidt JA, Oppenheim JJ. Interleukin 1: an immunological perspective. Annu Rev Immunol 1985; 3:263-87.

\title{
SPECIAL ARTICLE
}

\section{THE INCREASED NEEDS OF PATIENTS IN NURSING HOMES AND PATIENTS RECEIVING HOME HEALTH CARE}

\author{
Peter W. Shaughnessy, Ph.D., and Andrew M. Kramer, M.D.
}

\begin{abstract}
To evaluate the effects of Medicare's prospective payment system and Medicaid's preadmission regulations on long-term care, we constructed clinical profiles in 1982 and 1986 of about 500 randomly selected patients from each of three types of facilities: nursing homes with relatively high proportions of Medicare patients (highMedicare nursing homes; $n=23$ ), traditional nursing homes $(n=19)$, and home health agencies $(n=18)$. Data were obtained directly from the care givers on the medical problems, problems requiring skilled nursing, and functional problems of these representative patients from 12 states.
\end{abstract}

For Medicare patients in high-Medicare nursing homes, the prevalence of medical problems and problems requiring skilled nursing increased substantially, whereas the prevalence of functional problems remained relatively unchanged. For example, from 1982 to 1986 there was a marked increase in the frequency of tube feedings (21 to 29 percent), oxygen use (6 to 14 percent), urinary tract

$\mathrm{T}$ $\mathrm{HE}$ rising demand for geriatric and long-term care in the United States as a result of increases in the elderly population ${ }^{1,2}$ may be straining our already

From the Center for Health Services Research, University of Colorado Health Sciences Center, and the Department of Internal Medicine, University of Colorado School of Medicine, Denver. Address reprint requests to Dr. Shaughnessy at the Center for Health Services Research, Suite 706, 1355 South Colorado Blvd., Denver, CO 80222.

Supported by grants and cooperative agreements (18-P-97145/8-01, 18-C97712/8-04, and 15-C-98971/8-01) from the Health Care Financing Administration, and (14004) the Robert Wood Johnson Foundation. The opinions and recommendations reported here are those of the authors alone. infection ( 7 to 13 percent), and diastolic hypertension ( 1 to 10 percent), but not difficulty in eating ( 48 to 51 percent) or speaking (28 to 29 percent). In contrast, in traditional nursing homes there was an increase in the prevalence of functional disability, but virtually no change in that of problems requiring medical and skilled nursing care. In home health care the functional care needs of Medicare patients increased significantly, and there was a slight increase in the prevalence of problems requiring medical and skilled nursing care.

We conclude that from 1982 to 1986 the needs of patients in long-term care increased substantially. This trend appears to result from Medicare's prospective payment system, which encourages earlier hospital discharge to long-term care settings, and from Medicaid's policy of deinstitutionalization. Meeting this greater need for care will be costly. We require a better system of reimbursing for long-term care and ensuring its quality. ( $N$ Engl $J$ Med 1990; 322:21-7.)

overtaxed and fragmented long-term care delivery system. Anecdotal evidence suggests that recent Medicare and Medicaid reimbursement and regulatory practices have increased the need for patient care in nursing homes and home health agencies. Evidence of the effect of such practices on hospital care is now available ${ }^{3-6}$ but their effect, if any, on long-term care is unclear.

Implemented in 1983, Medicare's prospective payment system provides reimbursement based on diagnosis-related groups. It has reduced the length of stays 